\title{
Chloroxine overrides DNA damage tolerance to restore platinum sensitivity in high-grade serous ovarian cancer
}

Vera L. Silva', Jayeta Saxena ${ }^{1}$, Francesco Nicolini ${ }^{1}$, Joseph I. Hoare ${ }^{1}$, Stephen Metcalf', Sarah A. Martin $\mathbb{D}^{1}$ and Michelle Lockley (1D)

\begin{abstract}
High-grade serous cancer (HGSC) accounts for $~ 67 \%$ of all ovarian cancer deaths. Although initially sensitive to platinum chemotherapy, resistance is inevitable and there is an unmet clinical need for novel therapies that can circumvent this event. We performed a drug screen with 1177 FDA-approved drugs and identified the hydroxyquinoline drug, chloroxine. In extensive validation experiments, chloroxine restored sensitivity to both cisplatin and carboplatin, demonstrating broad synergy in our range of experimental models of platinum-resistant HGSC. Synergy was independent of chloroxine's predicted ionophore activity and did not relate to platinum uptake as measured by atomic absorption spectroscopy. Further mechanistic investigation revealed that chloroxine overrides DNA damage tolerance in platinum-resistant HGSC. Co-treatment with carboplatin and chloroxine (but not either drug alone) caused an increase in $\mathrm{YH} 2 \mathrm{AX}$ expression, followed by a reduction in platinum-induced RAD51 foci. Moreover, this unrepaired DNA damage was associated with p53 stabilisation, cell cycle re-entry and triggering of caspase 3/7mediated cell death. Finally, in our platinum-resistant, intraperitoneal in vivo model, treatment with carboplatin alone resulted in a transient tumour response followed by tumour regrowth. In contrast, treatment with chloroxine and carboplatin combined, was able to maintain tumour volume at baseline for over 4 months. In conclusion, our novel results show that chloroxine facilitates platinum-induced DNA damage to restore platinum sensitivity in HGSC. Since chloroxine is already licensed, this exciting combination therapy could now be rapidly translated for patient benefit.
\end{abstract}

\section{Introduction}

Ovarian cancer is the seventh most common cancer type amongst women ${ }^{1}$ and the most common histological subtype is high-grade serous cancer (HGSC) $)^{2}$. Standard treatment is still reliant on combination surgery and platinum-based chemotherapy ${ }^{3}$. Despite this aggressive approach, $85 \%$ of patients will subsequently relapse and sequential platinum treatment inevitably results in

\footnotetext{
Correspondence: Michelle Lockley (m.lockley@gmul.ac.uk)

${ }^{1}$ Centre for Cancer Cell and Molecular Biology, Barts Cancer Institute, Queen Mary University of London, London, UK

${ }^{2}$ Department of Gynaecological Oncology, Cancer Services, University College London Hospital, London, UK
}

Edited by R. Aqeilan chemotherapy resistance ${ }^{4}$. Circumventing this pervasive problem is an unmet clinical challenge.

Platinum compounds covalently bind DNA, generating protein-DNA or DNA-DNA complexes, along with inter- and intra-strand adducts ${ }^{5,6}$. This ultimately generates DNA lesions, followed by activation of the DNA damage response $(\mathrm{DDR})^{5,6}$. Apoptosis eventually occurs when damage exceeds repair. Platinum resistance is a multifactorial process that has been extensively investigated $^{7}$. Many potential mechanisms underlie this event, including failure to uptake or accumulate platinum ${ }^{8}$, augmented DNA damage repair machinery ${ }^{9}$, increased tolerance to unrepaired DNA lesions ${ }^{10}$, defects in signal transduction ${ }^{7}$, inactivation of pro-apoptotic events ${ }^{11}$ and upregulation of autophagic pathways ${ }^{6}$. The elucidation of

\section{(c) The Author(s) 2021}

(c) (i) Open Access This article is licensed under a Creative Commons Attribution 4.0 International License, which permits use, sharing, adaptation, distribution and reproduction cc) in any medium or format, as long as you give appropriate credit to the original author(s) and the source, provide a link to the Creative Commons license, and indicate if changes were made. The images or other third party material in this article are included in the article's Creative Commons license, unless indicated otherwise in a credit line to the material. If material is not included in the article's Creative Commons license and your intended use is not permitted by statutory regulation or exceeds the permitted use, you will need to obtain permission directly from the copyright holder. To view a copy of this license, visit http://creativecommons.org/licenses/by/4.0/. 
these mechanisms is yet to support the discovery of more efficient treatments for resistant $\mathrm{HGSC}^{3}$.

Repurposing non-oncological drugs for clinical applications is an exciting and cost-effective strategy that can provide rapid clinical translation ${ }^{12}$. We have previously developed a unique panel of platinum-resistant cell lines and in vivo models and shown that they closely resemble the genetic, transcriptional and clinical features of human $\mathrm{HGSC}^{13}$. Using these novel cell lines, we employed a drug screening approach to identify hit drugs that could potentially reverse platinum resistance. The compound library encompassed 1177 small molecules, 90\% of which are marketed drugs, many with unknown anticancer properties. We identified chloroxine, a 8-hydroxyquinoline (8-HQ) with antibacterial and antifungal activities $^{14}$. To our knowledge, there are no reports regarding the activity of chloroxine as an anticancer agent and very little is known about its inherent cellular mechanism.

Herein, we reveal for the first time, the synergy between chloroxine and platinum agents in resistant HGSC both in vitro and in vivo. We unravel the novel mechanism of action of chloroxine in overriding the inherent tolerance to DNA damage in platinum-resistant cancer cells and facilitating cancer cell death by apoptosis. Moreover, chloroxine showed tumour-static effect in vivo, when used in combination with carboplatin; thus, chloroxine could have significant impact on the treatment of patients with platinum-resistant HGSC.

\section{Materials and methods}

\section{Cell culture and platinum-resistant cell lines}

Human HGSC cell lines OVCAR4 and COV318 were obtained from Prof. Fran Balkwill (Barts Cancer Institute, UK). Platinum-resistant HGSC cell lines (Ov4Cis, Ov4Carbo and CovCis) were generated by serial culture in increasing concentrations of either cisplatin or carboplatin, as we described previously ${ }^{13}$ and subsequently cultured in drug-free media. Cells were grown at $37^{\circ} \mathrm{C}$ in a humidified incubator with 95\% air and 5\% $\mathrm{CO}_{2}$ in DMEM (Gibco) supplemented with 10\% FBS (Gibco) and 1\% penicillin/streptomycin (Gibco). All cell lines underwent 16-locus STR verification (DNA Diagnostics Centre, London, UK: February 2016 and European Collection of Authenticated Cell Lines August 2019) and weekly mycoplasma testing.

\section{Compound library screen}

To screen HGSC cell lines for existing drugs that synergise with carboplatin, we used a 96-well plate cell viability assay based on our previous work ${ }^{15}$. The chemical library encompassed 1177 small molecules, 90\% of which were marketed drugs, the remaining $10 \%$ being bioactive alkaloids. Platinum-sensitive (OVCAR4) and platinum-resistant (Ov4Carbo) cells were seeded in 96-well plates $\left(10^{3}\right.$ cells/well). On day 2 , cells were exposed to either a library compound or equimolar dimethyl sulfoxide (DMSO) vehicle control. On day 5, cells were re-treated with the same library compound together with either carboplatin $(5 \mu \mathrm{M})$ or vehicle. In all, $5 \mu \mathrm{M}$ carboplatin was chosen because this dose resulted in minimal cell death in both cell lines (Supplementary Fig. S1A). Each drug in the compound library was therefore tested alone and in combination with carboplatin in both cell lines, in one well of the 96-well plate per experimental condition. The final compound concentration used was $10 \mu \mathrm{M}$, based on our previous work ${ }^{15}$ as a dose in which the effects on cell viability are highly likely to be observed. We expected that many of the initial hit drugs, identified at this drug dose in only one well per experimental condition, would be excluded in subsequent validation experiments (see below).

After 7 days' continuous culture, cell viability in each well was estimated using a luciferase-based ATP assay (CellTitre-Glo, Promega) according to the manufacturer's instructions. For each well in the 96-well plate, the effect of treatment was represented as a log2-surviving fraction (s.f.) and expressed relative to the median s.f. for the entire 96-well plate. In each cell line, s.f. was compared between library-treated and vehicle-treated wells and also between wells treated with either library+carboplatin or carboplatin alone (Supplementary Table 1). To identify the selective ability to synergise with carboplatin, we predefined a cut-off of s.f. $<-2$ following library + carboplatin together with s.f. $>-2$ for library compound alone. Using these criteria, 11 drugs were considered 'hits' and selected for further investigation in validation experiments (Supplementary Table 2).

\section{Synergy validation experiments}

Validation experiments were carried out by plating OVCAR4 and Ov4Carbo cells in 96 -well plates $\left(10^{3}\right.$ cells/ well) in triplicate wells per condition. Cells were treated using the same experimental protocol as the initial compound library screen (day 2: hit drug $(1-10 \mu \mathrm{M})$ or vehicle, day 5: carboplatin $(0.01-1000 \mu \mathrm{M})+$ either hit drug (same dose as on day 2) or vehicle). Cell viability was again estimated using CellTitre-Glo on day 7. Dose-response curves were generated and $\mathrm{IC}_{50}$ calculated using GraphPad Prism v.8.0 (nonlinear regression fit to a fiveparameter equation). At least three biological repeat experiments were conducted per potential hit compound and analysed using Calcusyn ${ }^{\circledR}$ software to generate isobolograms where a CI (combination index) $>1$ indicates synergy, $\mathrm{CI}=1$ indicates addition and $\mathrm{CI}<1$ indicates antagonism. All 11 potential hit drugs (Supplementary Table 2) were tested in validation experiments. Chloroxine was selected for further investigation because it was the only drug that demonstrated synergy with platinum 
chemotherapy specifically in HGSCs with pre-existing resistance.

\section{Preparation of chloroxine in Intralipid}

Chloroxine (5,7-dichloro-8-quinolinol, Sigma-Aldrich) was weighed in amounts of 0 (blank), 10, 30, 50 and $100 \mathrm{mg} / \mathrm{kg}$ in separate glass vials. Larger clumps were broken down using a spatula. In total, $15 \mathrm{ml}$ of Intralipid emulsion (Sigma-Aldrich) was added to each glass vial, vortex-mixed for $5 \mathrm{~min}$ and bath-sonicated for at least $2 \mathrm{~h}$ at $40^{\circ} \mathrm{C}$. A previous report ${ }^{16}$ showed that there was no effect of bath sonication on the stability of these emulsions. Optimum solubility was obtained at $10 \mathrm{mg} / \mathrm{kg}$.

\section{Murine experiments}

OVCAR4 and Ov4Carbo cells were previously modified using lentiviruses to express dual GFP/Luciferase and RFP/ Luciferase reporters, respectively ${ }^{13}$. All experiments were conducted under UK government Home Office license (P1EE3ECB4) following Institutional Review Board approval. Cells were inoculated by intraperitoneal (IP) injection into 6week-old female $C D 1^{n u / n u}$ mice (Charles River Laboratories) in sterile PBS $\left(5 \times 10^{6}\right.$ cells $\left./ 200 \mu \mathrm{l}\right)$. Tumour growth was monitored weekly via bioluminescence using IP injections of D-Luciferin monopotassium salt $(3.7 \mathrm{mg} / 200 \mathrm{ml}$, ThermoFisher) in PBS. Light emission was recorded using an IVIS ${ }^{\circledR}$ Spectrum (PerkinElmer). Mice were randomly allocated (by order of cage number and existing earmarking) to treatment groups. In an initial optimisation experiment, mice received either carboplatin $(50 \mathrm{mg} / \mathrm{kg}$ in $0.2 \mathrm{ml}$ PBS IP weekly, $n=10)$ or PBS control $(0.2 \mathrm{ml}$ daily IP, $n=5)$. We then selected a sample size of five mice per group for our first in vivo evaluation of chloroxine-delivered IP in Intralipid. Mice in this second experiment received carboplatin $(50 \mathrm{mg} / \mathrm{kg}$ in $0.2 \mathrm{ml}$ PBS IP weekly, $n=5)$, chloroxine $(10 \mathrm{mg} / \mathrm{kg}$ in $0.2 \mathrm{ml}$ Intralipid IP once daily, $n=5$ ), combination (daily chloroxine and weekly carboplatin, $0.4 \mathrm{ml} \mathrm{IP}, n=5$ ) or PBS control $(0.2 \mathrm{ml}$ daily IP, $n=5)$. In both experiments, treatment commenced once tumours were established, as determined by our predefined light output cut-offs (average radiance between $10^{5}$ and $10^{7} \mathrm{p} / \mathrm{s} / \mathrm{cm}^{2} / \mathrm{sr}$ ). Three mice were excluded for not meeting these parameters (one from the carboplatin group, one from the combination group and once from the PBS control group). The appearance of chloroxine in Intralipid solution (see Fig. 2B) prevented blinding of experimental groups. Treatment continued for 4 weeks. Mice were assessed for weight, general health and accumulation of ascites, and were killed once they reached humane endpoint (defined by the UK Home Office guidelines).

\section{Platinum uptake}

In total, $1 \times 10^{6}$ OVCAR4 and Ov4Carbo cells were plated in 10-cm dishes (Corning) and treated after $24 \mathrm{~h}$ with $10 \mu \mathrm{M}$ chloroxine, $100 \mu \mathrm{M}$ carboplatin or both drugs combined. Up to $48 \mathrm{~h}$ later, cells were washed twice with ice-cold PBS. Cells were scraped into $200 \mu \mathrm{l}$ lysis buffer (150 mM NaCl, $50 \mathrm{mM}$ Tris, $0.05 \%$ SDS and 1\% triton). In total, $20 \mu \mathrm{l}$ lysate was collected for protein quantification (Pierce bicinchoninic acid (BCA) kit (Thermo Scientific)). The remainder was spun $\left(13,000 \times g\right.$ at $4{ }^{\circ} \mathrm{C}$ for $\left.5 \mathrm{~min}\right)$ and the supernatant (whole-cell fraction) collected. Samples were adjusted to $1 \mathrm{ml}$ with $0.5 \%$ nitric acid $\left(\mathrm{HNO}_{3}\right)$ to ensure platinum (Pt) solubilisation. Pt content was analysed using atomic absorption spectroscopy, AAS (Varian Spectra AAS 220 FS) with a hollow cathode platinum lamp operated at $10 \mathrm{~mA}$. Platinum absorbance was monitored at $265.9 \mathrm{~nm}$ corrected for any background signals, with a slit width of $0.2 \mathrm{~nm}$. Argon was used as the inert gas with a constant flow of $3 \mathrm{ml} / \mathrm{min}$. Elemental platinum standards $(20-1000 \mu \mathrm{g} / \mathrm{L})$ were prepared by serial aqueous dilution using High-Purity Standards platinum standard $(1000 \mu \mathrm{g} / \mathrm{ml}$, Sigma-Aldrich $)$ and carboplatin stock $(10 \mathrm{mg} / \mathrm{ml})$. In all, $20 \mu \mathrm{l}$ samples were injected for three measurements per sample on two dishes per condition in duplicate experiments. Pt concentrations were determined by applying an elemental platinum standard curve and normalised to protein levels.

\section{Copper complexation}

$\mathrm{Cu}-8$-HQ (chloroxine) complexes were prepared as described previously ${ }^{17}$. Two equivalents of chloroxine (20 mg, $0.0935 \mathrm{mmol}$ ) were added slowly to a stirred solution of $\mathrm{CuCl}_{2}(8 \mathrm{mg}, 0.0468 \mathrm{mmol})$ in $10 \mathrm{ml}$ of an ethanolic solution and stirred for over $3 \mathrm{~h}$. To assess cytotoxicity, OVCAR4 and Ov4Carbo cells (1000/well) were plated in 96-well plates in triplicate and treated with cupric chloroxine $(10 \mu \mathrm{M}) \pm$ carboplatin as before (see synergy validation, $n=3$ biological repeats). Cell viability was determined using CellTiter-Glo and dose-response curves generated.

\section{Copper enrichment assays}

To simulate the in vivo copper status of cancer cells, OVCAR4 and Ov4Carbo cells were cultured in media containing $25 \mu \mathrm{M} \mathrm{CuCl} 2$ for 1 week, as previously described $^{18}$. Cells (1000/well) were then plated in 96-well plates and treated with chloroxine $(10 \mu \mathrm{M}) \pm$ carboplatin in triplicate as before (see synergy validation, $n=3$ biological repeats). For short-term enrichment, cells were plated in 96-well plates and pre-treated with $10 \mu \mathrm{M} \mathrm{CuCl}_{2}$ for $48 \mathrm{~h}$. Cell viability was determined on day 7 using CellTiter-Glo and dose-response curves generated.

\section{OPRK1}

OVCAR4 and Ov4Carbo cells (1000/well in triplicate) were seeded in 96-well plates (triplicate) and treated with chloroxine $(10 \mu \mathrm{M}) \pm$ carboplatin as before (see synergy validation, $n=8$ biological repeats). The selective $\mathrm{k}$-opioid 
agonist: U50,488 (( \pm )-trans-U-50488 methanesulfonate salt, Sigma-Aldrich) and antagonist: nor-binaltorphimine (nor-BNI, Sigma-Aldrich) were used at $10 \mu \mathrm{M}$ in place of chloroxine and in combination with carboplatin on day 5 . Control plates displaying dose-response curves for each individual compound were seeded in parallel. Cell viability was determined on day 7 using CellTiter-Glo assay and dose-response curves generated.

\section{Western blot}

OVCAR4 and Ov4Carbo $\left(4 \times 10^{5}\right.$ cells/well $)$ were seeded in six-well plates. Cells were washed with PBS and sonicated (Bioruptor Pico-RM 343 for $10 \mathrm{~min}$ ) in ice-cold lysis buffer $(150 \mathrm{mM} \mathrm{NaCl}, 50 \mathrm{mM}$ Tris, $0.05 \%$ SDS and $1 \%$ triton), supplemented with $1 \%$ protease/phosphatase inhibitor cocktail (Roche). Samples were centrifuged $\left(13,000 \times g, 4{ }^{\circ} \mathrm{C}, 20 \mathrm{mins}\right)$ and protein concentration determined (Pierce BCA assay kit (Thermo Scientific)). In total, $30 \mu \mathrm{g} / 20 \mu \mathrm{l}$ protein were prepared in SDS loading buffer, boiled for $5 \mathrm{~min}$, separated on $4-12 \%$ Bis-Tris gels (Life Technologies) and transferred to nitrocellulose membranes (GE Healthcare) by semi-dry transfer (TransBlot ${ }^{\circledR}$ SD Cell, BioRad). Membranes were blocked in 5\% non-fat milk/PBS for $1 \mathrm{~h}$ at room temperature and incubated with primary antibodies for p53 (1:1000, Sc-126 Santa Cruz, $n=4$ biological repeats), RAD51 (1:1000, PA5-27195, Invitrogen, $n=3$ biological repeats), GADPH (1:2000, Sc-47724 Santa Cruz), Tubulin (1:2000, ab52866 Abcam) and $\gamma \mathrm{H} 2 \mathrm{AX}$ (ser139 1:500, JBW301 Millipore, $n$ $=8$ biological repeats) at $4{ }^{\circ} \mathrm{C}$ overnight, followed by incubation with secondary anti-mouse HRP (1:2000, P0260 DAKO) and anti-rabbit HRP (1:1000, P0448 DAKO) for $1 \mathrm{~h}$ at room temperature. Proteins were visualised by enhanced chemiluminescence (GE Healthcare), imaged (Amersham Image 600, GE Healthcare) and quantified by densitometry (ImageQuant TL software package).

\section{Immunofluorescence for DNA damage}

OVCAR4 and Ov4Carbo cells $\left(8 \times 10^{4}\right.$ cells/well $)$ were seeded in duplicate on poly-l-lysine-coated coverslips and allowed to adhere overnight. Cells were then treated with chloroxine $(10 \mu \mathrm{M})$, carboplatin $(50 \mu \mathrm{M}$ or $100 \mu \mathrm{M})$ or combination [(chloroxine $(10 \mu \mathrm{M})+$ carboplatin $50 \mu \mathrm{M}$ or $100 \mu \mathrm{M})]$ for 4 and $24 \mathrm{~h}$. The medium was aspirated and $0.1 \%$ Triton (Sigma-Aldrich) in PBS added for $1 \mathrm{~min}$ prior to fixing in $3 \%$ paraformaldehyde $/ 2 \%$ sucrose for $30 \mathrm{~min}$. Cells were then blocked with 3\% BSA/PBS for $1 \mathrm{~h}$. Next, staining was performed with antibodies for $\gamma \mathrm{H} 2 \mathrm{AX}$ (1:800, Millipore JBW301) and RAD51 (1:1000, Invitrogen PA5-27195) for $40 \mathrm{~min}$ at $37^{\circ} \mathrm{C}$. Cells were incubated with secondary antibodies (AlexaFluor-488 and AlexaFluor568, Invitrogen) for $30 \mathrm{~min}$ at $37^{\circ} \mathrm{C}$, and co-stained with DAPI $(1: 10,000, \quad 1 \mathrm{mg} / \mathrm{ml}$ Sigma). Coverslips were mounted with Mowiol and images captured using a Zeiss 710 confocal microscope. Foci were counted and scored manually using ImageJ software. At least 100 nuclei were counted for each condition (using duplicate plate wells) and cells with $>5$ foci/nucleus were considered positive (three biological replicates were conducted).

\section{Flow cytometry (cell cycle)}

Cells were treated with chloroxine $(10 \mu \mathrm{M})$, carboplatin $(100 \mu \mathrm{M})$ or the combination (chloroxine $10 \mu \mathrm{M}+$ carboplatin $100 \mu \mathrm{M}$ ) and triplicate samples were harvested $24 \mathrm{~h}$ and $48 \mathrm{~h}$ post treatment in two biological repeat experiments. Cells were centrifuged $(1000 \times g$ for $5 \mathrm{~min})$, washed three times with cold PBS and fixed in 70\% (v/v) ethanol/PBS. Next, cells were re-suspended in $0.25 \mathrm{ml}$ PBS containing $25 \mu \mathrm{g}$ RNase and $12.5 \mu \mathrm{g}$ propidium iodide. Following $30 \mathrm{~min}$ of incubation at $37^{\circ} \mathrm{C}$, cell cycle profiles were acquired with LSR Fortessa ${ }^{\mathrm{TM}}$ (BD Biosciences), using a 670-nm long-pass filter and counting 10,000 cells per sample. Data were analysed using Flowjo v8.

\section{Caspase $3 / 7$ assay}

The synergy validation protocol detailed above was used to determine caspase 3/7 activity. Briefly, 1000 cells were plated, in triplicate, in 96-well plates and treated with chloroxine $(1-50 \mu \mathrm{M})$, carboplatin $(10-300 \mu \mathrm{M})$ or with the combination. Caspase $3 / 7$ activity was determined using Caspase-Glo ${ }^{\circledR}$ 3/7 Assay System (Promega) up to 7 days later. Duplicate plates were seeded to determine cell viability using CellTiter-Glo and three biological repeats were carried out.

\section{Statistics}

All data were presented as mean \pm s.d. and analyses were performed using GraphPad Prism 8.0. Groups were compared to establish comparable variance and statistical significance was calculated using a two-tailed unpaired $t$ test, one-way ANOVA (followed by post hoc Kruskal-Wallis test) or two-way ANOVA (followed by Tukey post hoc test) for group analysis and defined as

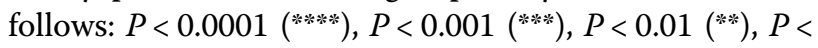
0.05 (*) or $P>0.05$ (ns). $n$ refers to biological replicates and the established scientific standard of $n \geq 3$ was applied throughout.

\section{Results}

Chloroxine synergises with carboplatin in platinumresistant HGSC in vitro

We employed a library of 1177 compounds to identify drugs that can restore sensitivity to carboplatin in HGSC $^{15}$. Cell viability was assessed using CellTiter-Glo ${ }^{\circledR}$ and the effect of each compound was determined by comparing luminescence output following drug, 

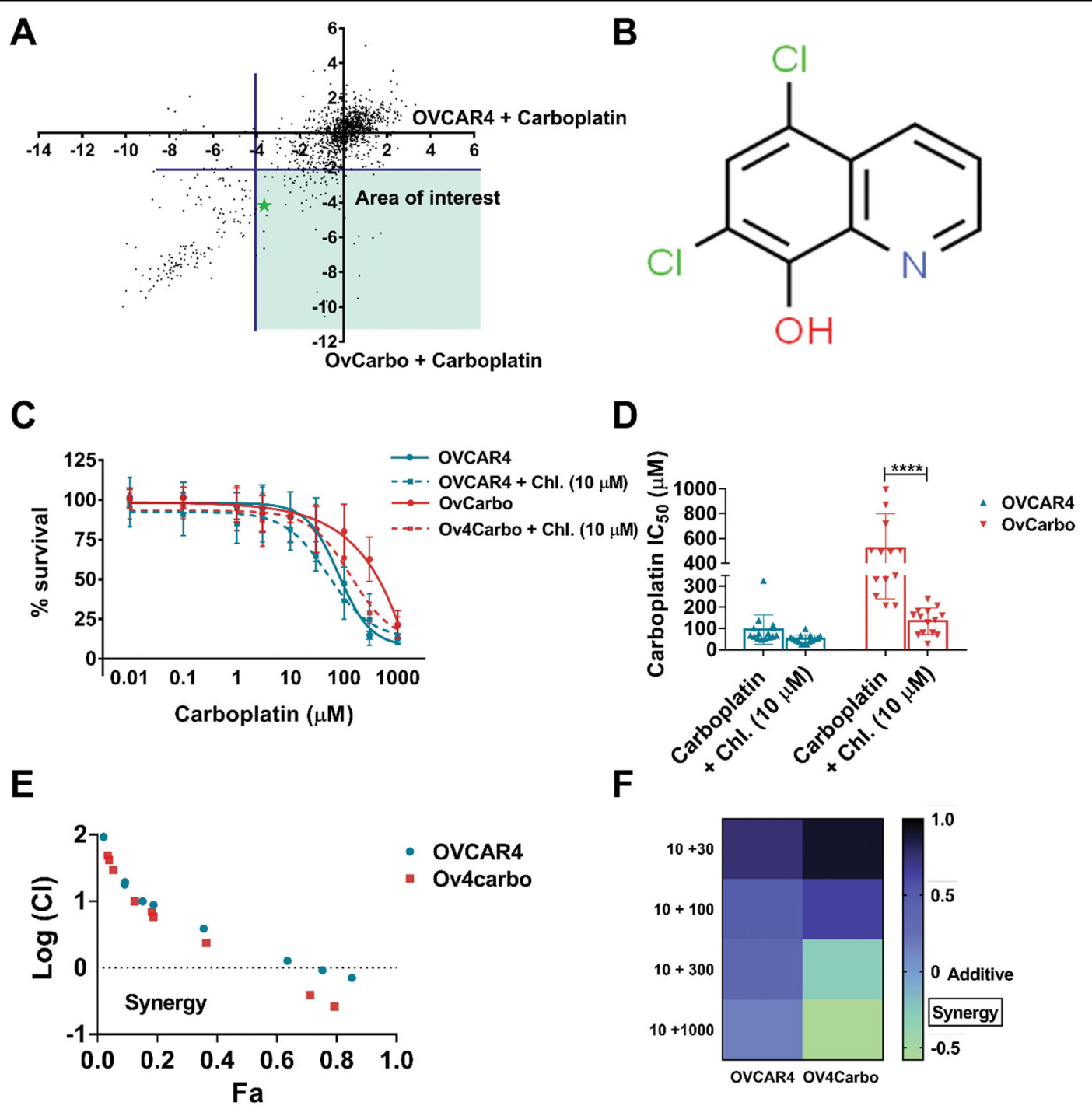

$\mathbf{F}$

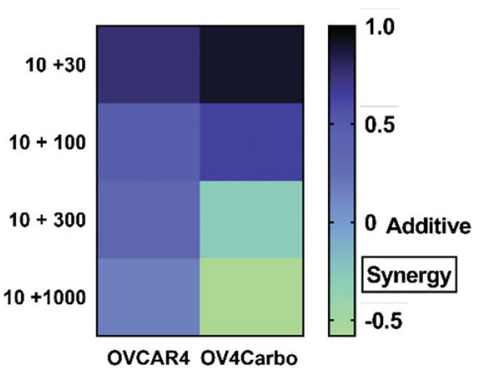

Fig. 1 Drug screen and in vitro synergy between chloroxine (Chl. $10 \mu \mathrm{M})$ and carboplatin on the viability of OVCAR4 (sensitive) and Ov4Carbo (resistant) ovarian cancer cells. A z-score (surviving fraction, s.f.) plot evidencing drug screen output. Each black dot represents one small-molecule drug in the library. Potential hits are highlighted in the area of interest (green star indicates target drug: chloroxine). B Chemical structure of 5,7-dichloro-8-quinolinol (chloroxine). C Carboplatin dose response. D IC 50 plot. E Fa-Cl plot or Chou-Talalay displaying combination index (in log) vs. fraction of affected cells (Fa); $\mathbf{F}$ heatmap demonstrating synergy in multiple biological repeats $(n=13)$. Cell viability was determined using CellTiter-Glo ${ }^{*}$. IC 50 was calculated using GraphPad Prism v.8.3.0. mean \pm s.d, unpaired $t$ test, ${ }^{* * * *} P<0.0001$. The combination index (Cl) was determined using Calcusyn software, where values $<1$ (log 0$)$ reflect drug synergy.

carboplatin, drug + carboplatin and vehicle treatment in OVCAR4 and Ov4Carbo cells. This effect was represented as a $\log _{2}$-surviving fraction (s.f.) and expressed relative to the median s.f. for the entire 96-well plate (Fig. 1A and Supplementary Table 1). In total, 11 potential "hit" compounds were identified that fulfilled our predefined criteria of s.f. $<-2$ following library + carboplatin together with s.f. $>-2$ for library compound alone (Supplementary Table 2). All 11 compounds were tested in validation experiments and only chloroxine (Fig. 1B) was validated as a "hit".
Chloroxine potentiated the effect of carboplatin in Ov4Carbo (carboplatin-resistant) cells in multiple repeat experiments (Fig. 1C, D). To determine if this combination was additive or synergistic, we analysed individual and combinatorial drug effects using CompuSyn software $^{19}$. Chou-Talalay isobolograms (Fig. 1E) showed that the combination of chloroxine and carboplatin was synergistic at chloroxine doses of $10 \mu \mathrm{M}$ and above (Supplementary Fig. S1), and that synergy was superior in carboplatin-resistant compared to -sensitive cells (Fig. 1F). These data strongly support chloroxine as a candidate 
drug to restore carboplatin sensitivity in HGSC. Importantly, the striking synergistic effect of chloroxine was also observed with cisplatin in additional platinum-resistant HGSC cell lines, including Ov4Cis (Supplementary Fig. S2A, B) and CovCis (Supplementary Fig. S2C, D).

\section{Chloroxine stabilises tumour burden in carboplatin- resistant intraperitoneal xenografts}

To assess chloroxine's activity in vivo, clinically relevant HGSC orthotopic intraperitoneal models were created, as we previously described ${ }^{13}$. The predetermined in vivo treatment and tumour surveillance schedule are depicted in Fig. 2A. Chloroxine solubility was limited in saline and so was prepared instead in a $20 \%$ intralipid solution (as previously described for other hydroxyquinolines $)^{20}$ at concentrations equivalent to $10,30,50$ and $100 \mathrm{mg} / \mathrm{kg}$. Well-solubilised solutions were observed up to $30 \mathrm{mg} / \mathrm{kg}$ (Fig. 2B).

HGSC IP xenografts were then created in female nude mice (day 0) using Ov4Carbo-resistant cells expressing firefly luciferase (Luc). Tumour growth was monitored with weekly bioluminescence imaging (BLI), and mice were killed when they reached humane endpoints predefined by the UK Home Office. Mice bearing established tumours on day 19 (average radiance $10^{5}-10^{7} \mathrm{p} / \mathrm{s} / \mathrm{cm}^{2} / \mathrm{sr}$ ) (Fig. 2C) were randomly allocated into four treatment groups on day 21. Animal numbers were insufficient to compare survival between the treatment groups. However, we observed that chloroxine-treated mice depicted a steady increase in tumour growth over time, comparable to that of the vehicle-treated group (Fig. 2C, D). Ov4Carbo-Luc xenografts initially responded to carboplatin, but subsequently developed resistance to treatment and light emission increased from day 70 onwards, such that it overlapped with vehicle-treated control mice. In contrast, when chloroxine was used in combination with carboplatin, light output was maintained at baseline (average radiance below $10^{3} \mathrm{p} / \mathrm{s} / \mathrm{cm}^{2} / \mathrm{sr}$ ) for the duration of the experiment (Fig. 2C, D). Thus, the combination of chloroxine and carboplatin had an overall tumour-static effect (average tumour radiance at endpoint $1.71 \times 10^{2}$ $\mathrm{p} / \mathrm{s} / \mathrm{cm}^{2} / \mathrm{sr}$ ) compared to the carboplatin monotherapy

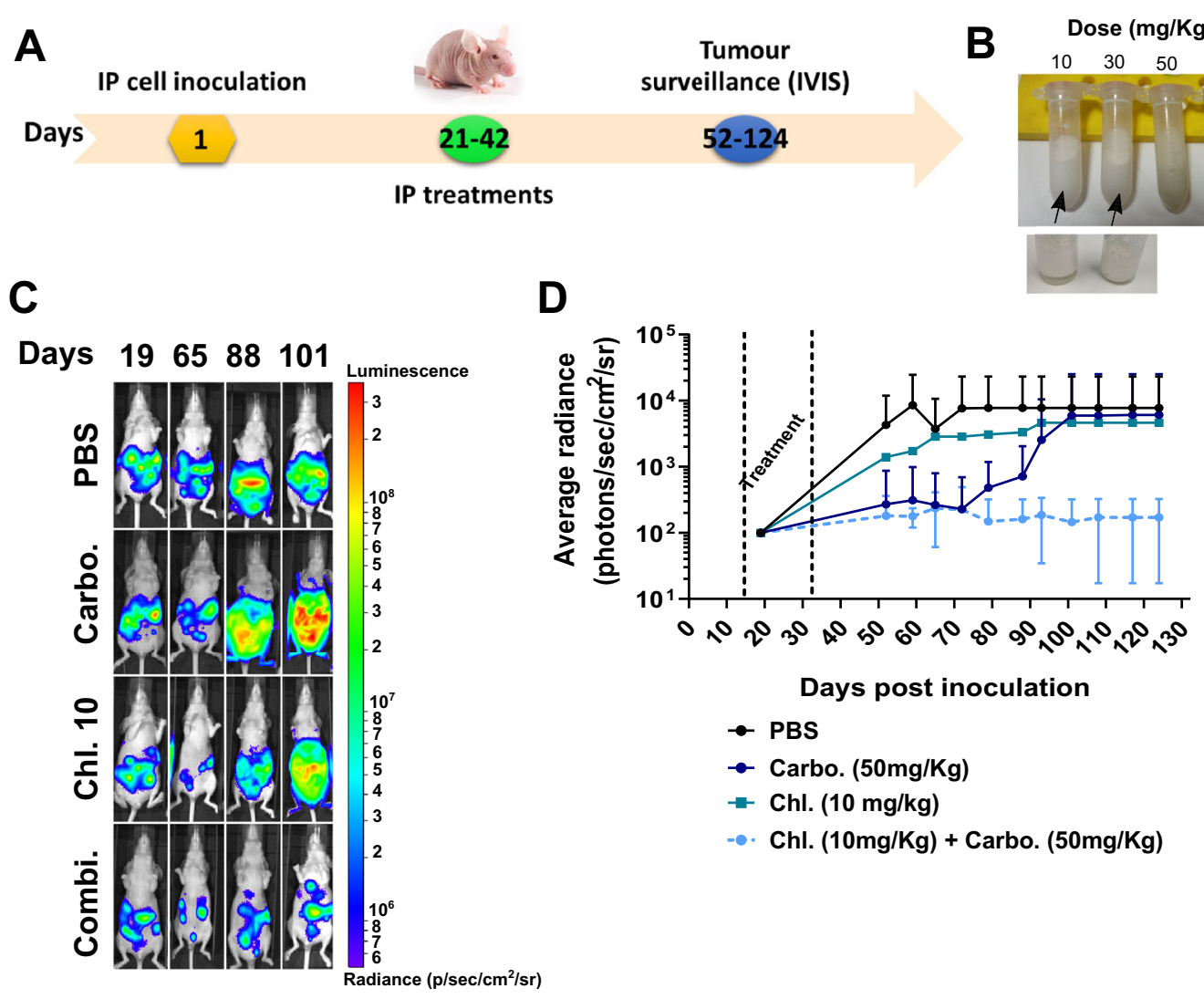

Fig. 2 In vivo activity for the combination of chloroxine $(\mathrm{Chl} .10 \mathrm{mg} / \mathrm{kg})$ and carboplatin $(50 \mathrm{mg} / \mathrm{kg})$ in intraperitoneal Ov4Carbo xenografts. A Schematic of in vivo schedule, including treatment and bioluminescence imaging timeframe. B Representative images highlighting maximum solubility of chloroxine $(\leq 30 \mathrm{mg} / \mathrm{kg}$ ) in intralipid $20 \%$. C Representative bioluminescence images pre- and post treatment and light emission over time. IP xenografts were created in female CD1 ${ }^{n u / n u}$ mice by injecting Ov4Carbo-Luc $\left(5 \times 10^{6}\right.$ cells per mouse). D Data depict different treatment groups showing mean \pm s.d., $n=4-14$. 
group (average tumour radiance at endpoint $6.07 \times 10^{3} \mathrm{p} /$ $\left.\mathrm{s} / \mathrm{cm}^{2} / \mathrm{sr}\right)$.

\section{Chloroxine binds copper, but carboplatin synergy is independent of its ionophore activity}

8-hydroxyquinolines depict strong metal $\mathrm{CCu}^{2+}$ and $\mathrm{Zn}^{2+}$ ) binding activity ${ }^{17,20,21}$ that leads to proteasome inhibition $^{22}$, lysosome destabilisation ${ }^{23}$, ROS generation and ultimately cell death. To investigate whether chloroxine can also exhibit such activity, a chloroxine solution was mixed in a 2:1 molar ratio with $\mathrm{CuCl}_{2}$. An intense colour change was observed ${ }^{18}$, confirming the chemical reaction typical for metal complex binding (Fig. 3A, inset). We then sought to determine if this cupric-chloroxine complex had relevant in vitro activity. When cells were treated with the copper-chloroxine complex for $72 \mathrm{~h}$, potentiation of chloroxine cytotoxicity was observed (Fig. $3 \mathrm{~A}$ ), confirming that chloroxine can act as an ionophore. However, when the copper-chloroxine complex was used in combination with carboplatin, we observed a dramatic reduction in cell viability. Raw luminescence units following treatment with the copper-chloroxine complex were extremely low $(<2000)$ preventing further interpretation of any difference between the resulting normalised values (Fig. 3B). These experiments demonstrate that this complex behaves as a new cytotoxic metal compound rather than mimicking chloroxine's synergistic interaction with carboplatin.

To further investigate whether this ionophore activity could be responsible for the synergy we had observed, we reproduced a more physiologically relevant copper environment in vitro by culturing cells in copper-enriched media $(10 \mu \mathrm{M})$ for $48 \mathrm{~h}$ prior to CellTiter-Glo assays. Although the synergistic interaction of chloroxine and carboplatin was once again verified, copper enrichment failed to alter the activity of carboplatin alone and did not influence its interaction with chloroxine in both OVCAR4 (Fig. 4A) and Ov4Carbo cells (Fig. 4B). We also verified that $\mathrm{CuCl}_{2}$ alone was non-toxic (Supplementary Fig. S3A) and contrary to the complexation assays (Fig. 3A), copper-enriched media did not alter the toxicity profile of chloroxine (Supplementary Fig. S3B, C). Furthermore, enrichment assays using higher copper concentrations $(25 \mu \mathrm{M}$ and $100 \mu \mathrm{M})$ in short- (48 h) and long-term supplementation (7 days) assays also failed to show any effect on drug synergy (data not shown). These experiments imply that chloroxinemediated ionophore activity is unlikely to be responsible for the synergy with carboplatin that we had observed.

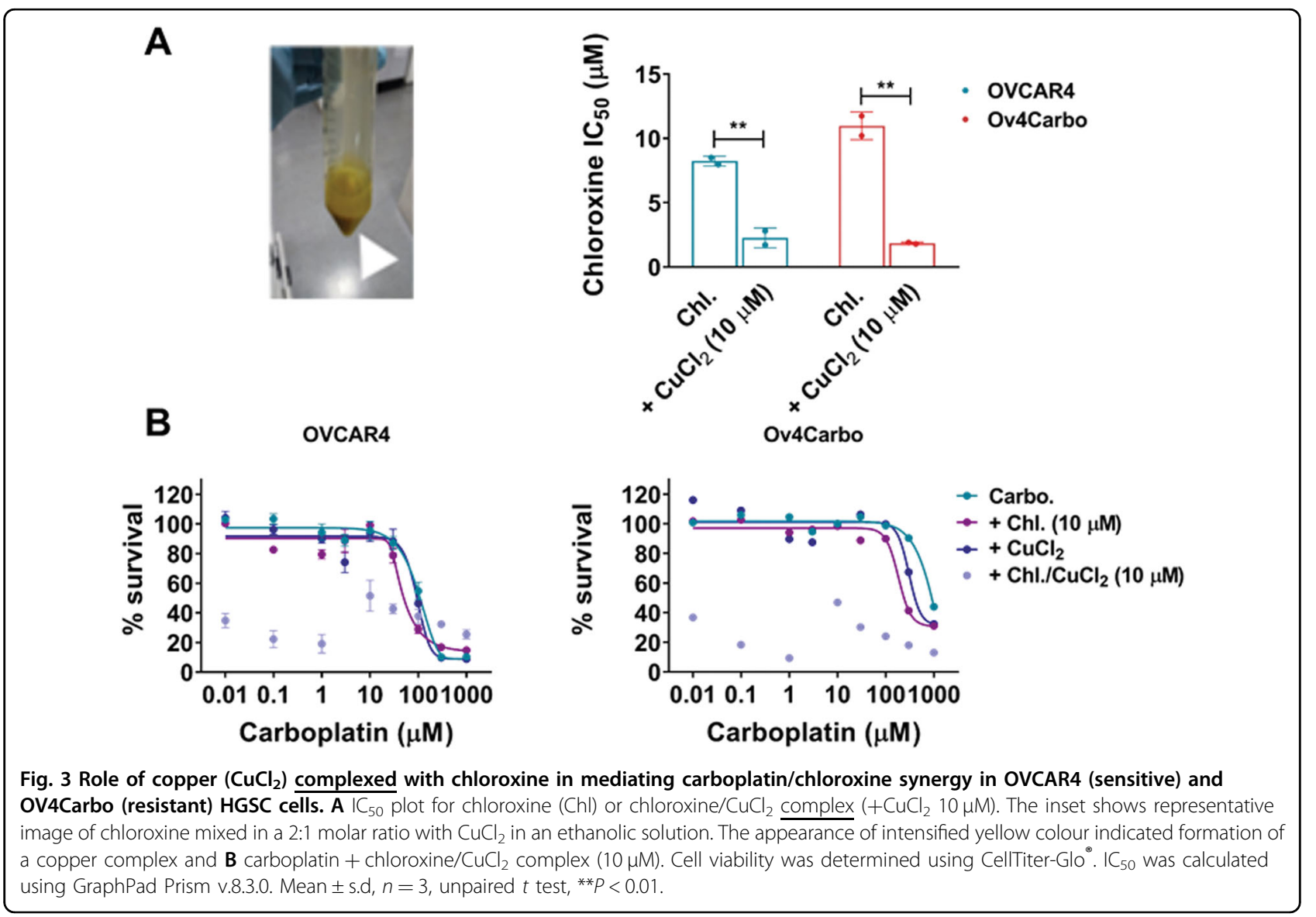



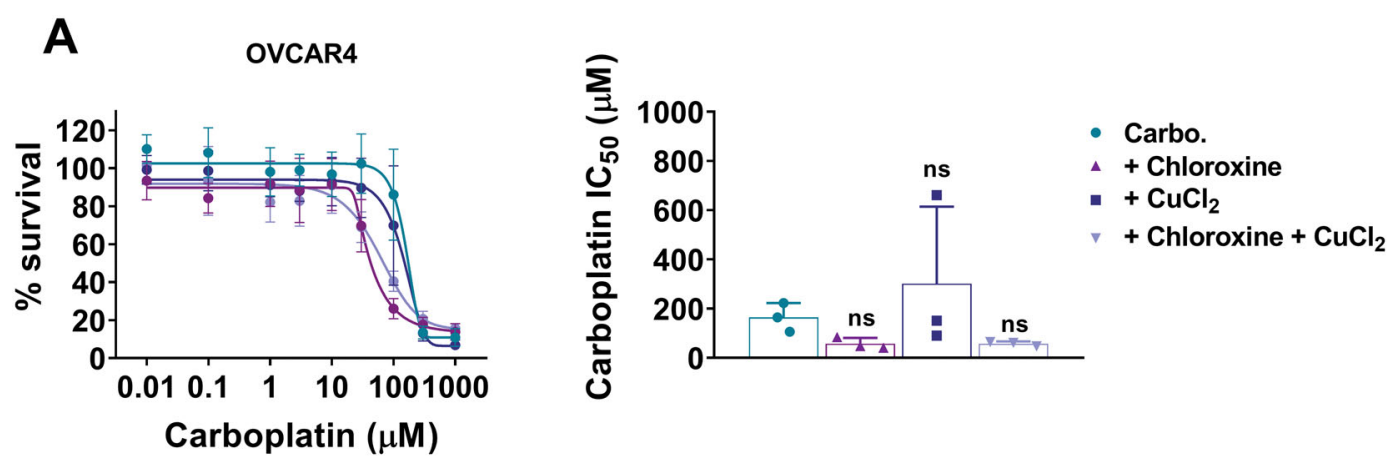

B
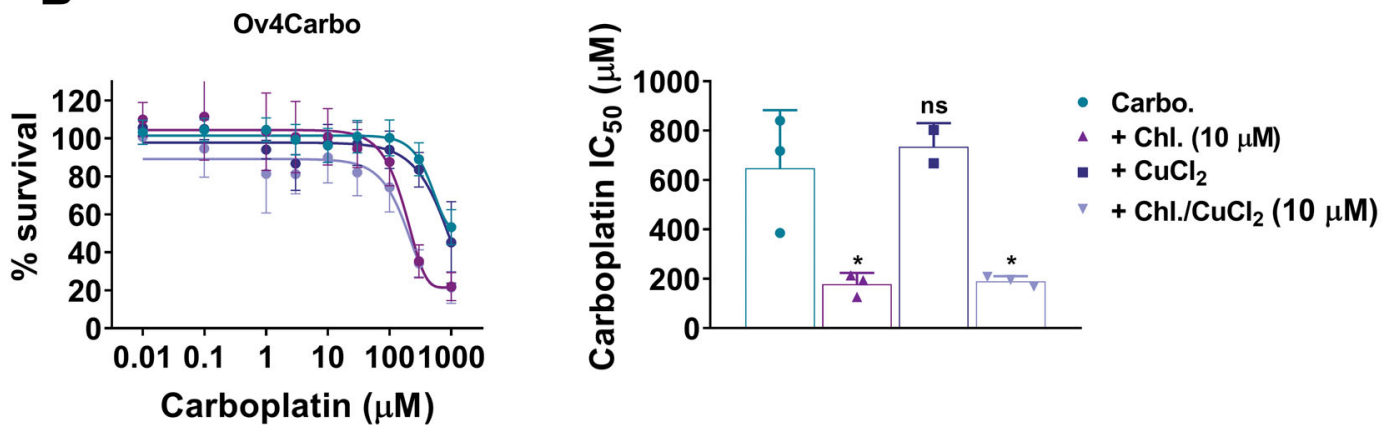

Fig. 4 Role of copper $\left(\mathrm{CuCl}_{2}\right.$ )-enriched media in mediating carboplatin/chloroxine synergy in OVCAR4 (sensitive) and OV4Carbo (resistant) HGSC cells. For enrichment assays, dose-response and $I_{50}$ plot for carboplatin + chloroxine $(10 \mu \mathrm{M})$ were determined in media enriched with $\mathrm{CuCl}_{2}$ $(10 \mu \mathrm{M})$ for $48 \mathrm{~h}$, in A OVCAR4 and B Ov4Carbo cells. Cell viability was determined using CellTiter-Glo . IC 50 was calculated using GraphPad Prism v.8.3.0. Mean $\pm s . d, n=3$, group analysis was performed using one-way ANOVA with post hoc Kruskal-Wallis test, ${ }^{*} P<0.05$, ns not significant.

\section{Chloroxine does not alter platinum uptake or OPRK1 activity in vitro}

Platinum uptake is mediated by both passive diffusion and active transporters, and cells that fail to successfully accumulate platinum, either by reduced import or excessive export, have been shown to develop resistance ${ }^{8}$. We measured whole-cell concentrations of platinum using AAS (atomic absorption spectroscopy) after drug treatment. Based on previous experimental procedures ${ }^{24}$, we found that cell pellets treated with lysis buffer containing $0.05 \% \mathrm{SDS}, 1 \%$ triton and $0.5 \% \mathrm{HNO}_{3}$ yielded excellent recovery of platinum $(\mathrm{Pt})$ signal (Supplementary Fig. 5A). Standard curves confirmed the validity and linearity of our assay $\left(Y=0.00187-0.054, R^{2}=0.9908\right)$ by showing that carboplatin stock standards yielded equal Pt signal to that of gold-standard Pt stocks. After carboplatin treatment, platinum uptake was observed in both OVCAR4 and Ov4Carbo cells, while vehicle- and chloroxine-treated samples maintained baseline, background signal for the duration of the experiment (Supplementary Fig. 5B, C). There was no significant difference in platinum uptake between the two cell lines. Further, the combination of chloroxine and carboplatin did not influence Pt uptake, suggesting that synergy is not dependant on intracellular Pt accumulation.
Two previous reports have described a possible function of chloroxine as an inhibitor of the kappa opioid receptor, OPRK $1{ }^{25,26}$. To explore whether synergy between chloroxine and carboplatin was mediated by OPRK1, we repeated our established synergy assays with the addition of an OPRK1 agonist (U50, 488) and antagonist (nor-BNI). U50,488 $(10 \mu \mathrm{M})$ did not alter carboplatin sensitivity (Fig. 5D, dark-blue bar) and failed to reverse chloroxine's synergistic effect (Fig. 5D, light-grey bar). In addition, the selective antagonist, nor-BNI ${ }^{27}$, also did not alter the dose response to carboplatin (Fig. 5E, dark-blue bar), and had no effect on chloroxine's synergy with carboplatin (Fig. 5E, light-grey bar). Taken together, these compounds did not affect the cytotoxicity for carboplatin or the synergy we observed between carboplatin + chloroxine $(10 \mu \mathrm{M})$ (see also Supplementary Fig. S4), implying that chloroxine was not potentiating the effect of carboplatin through OPRK1mediated signalling pathways.

Chloroxine in combination with carboplatin regulates the $\mathrm{Y}$-H2AX-RAD51 axis and stabilises p53 in platinum-

resistant cells

We next evaluated the formation of DNA double-strand breaks (DSB) and repair using the gold-standard markers, $\gamma \mathrm{H} 2 \mathrm{AX}$ and $\mathrm{RAD} 51^{28}$. Cells with $>5$ foci/nucleus were 


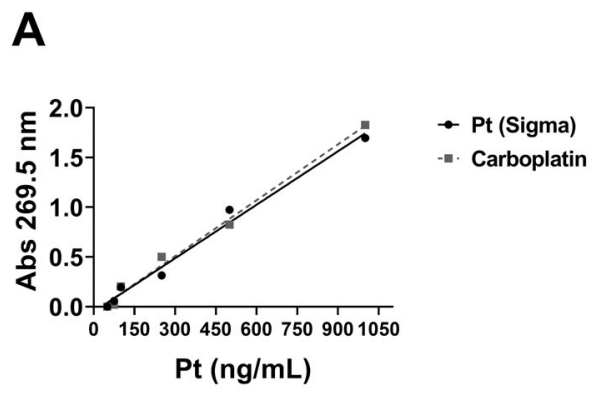

B

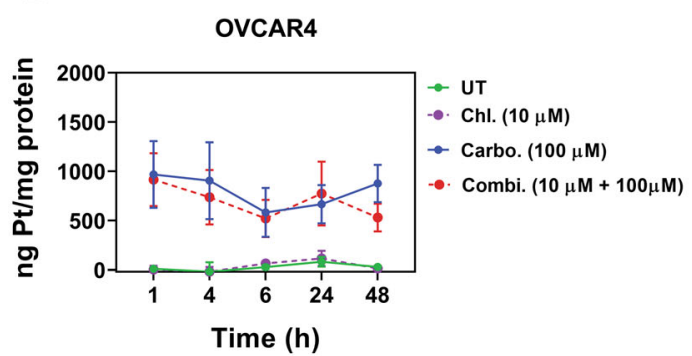

D

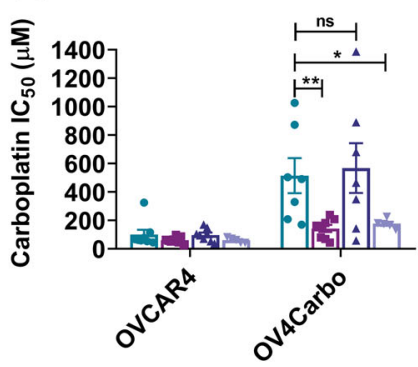

C

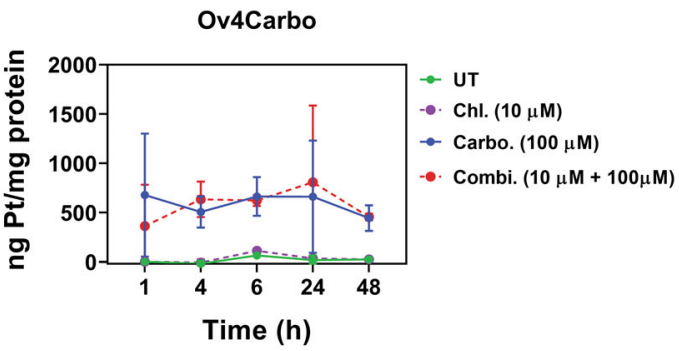

E 

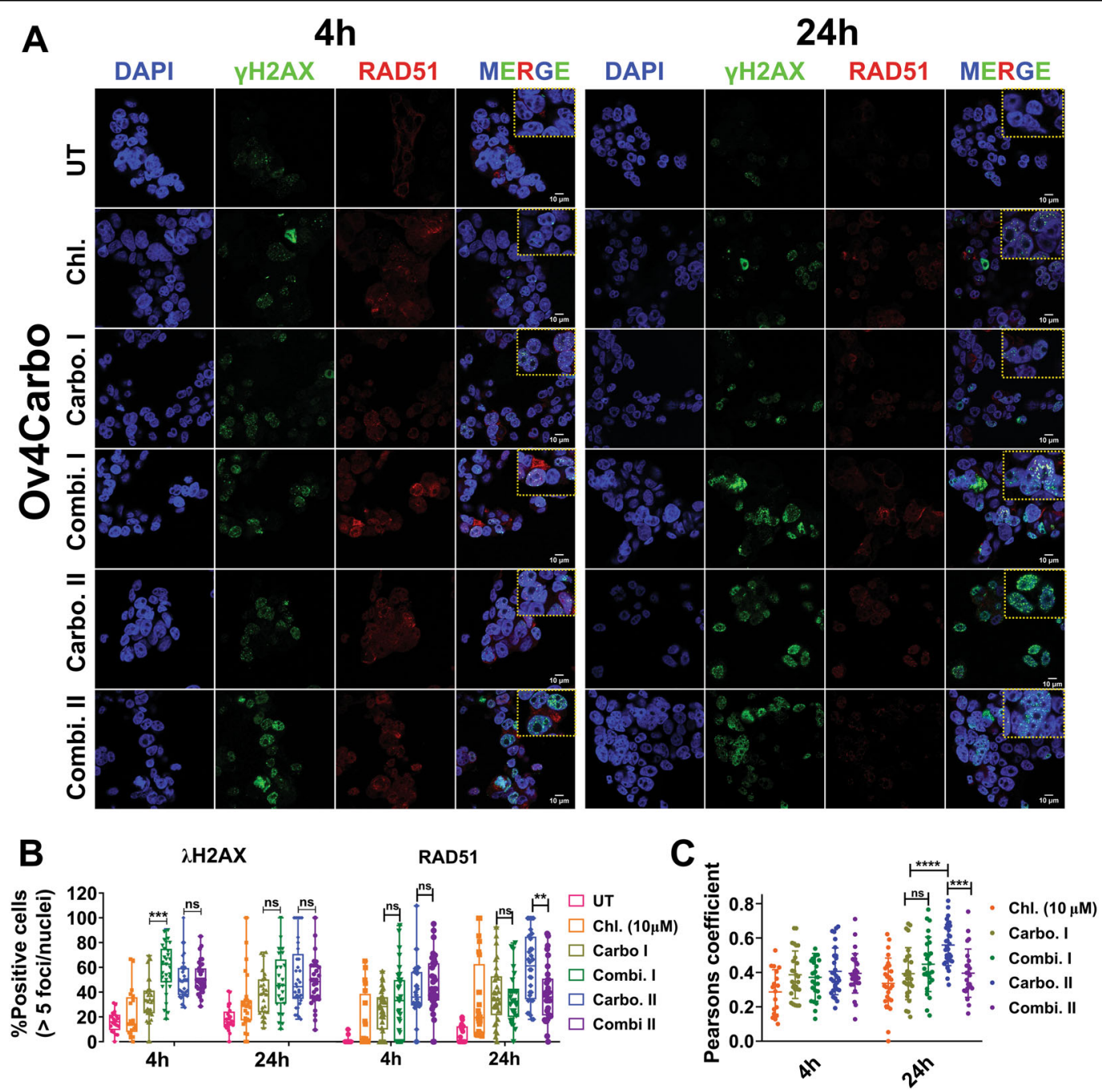

D
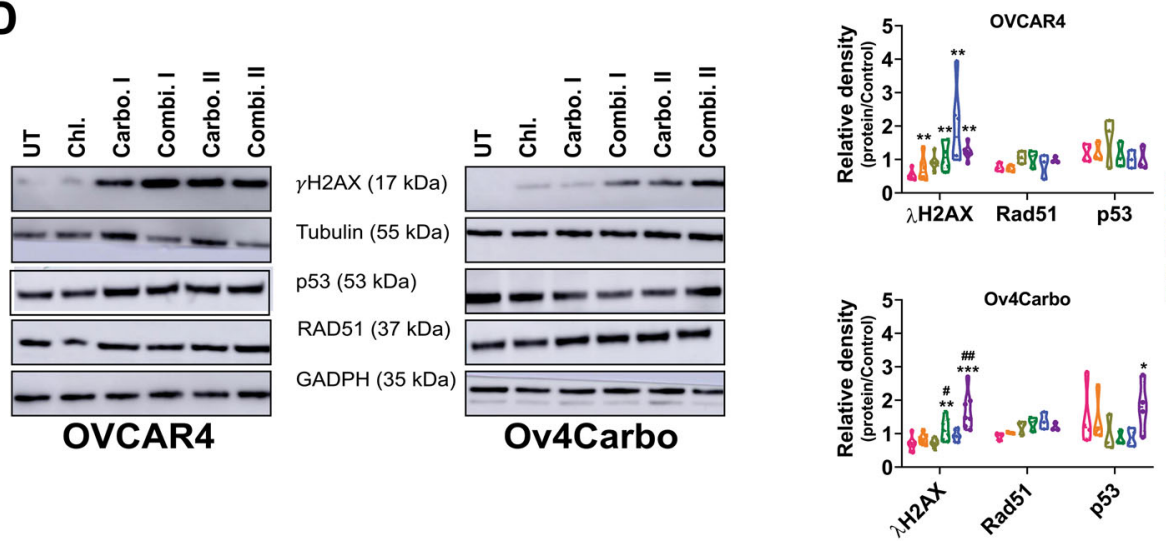

Fig. 6 Subcellular analysis of $\mathrm{YH} 2 \mathrm{AX}, \mathrm{RAD} 51$ and p53 as markers of DNA damage/repair in Ov4Carbo (resistant) ovarian cancer cells. A Representative immunofluorescent staining of $\mathrm{YH} 2 \mathrm{AX}$ and RAD51, B foci quantification and C dot plot for Pearson's correlation coefficients representing co-localisation analysis after 4 and $24 \mathrm{~h}$ of treatment. (D) Representative immunoblots and densiometric analysis (normalised to tubulin or GADPH), depicting YH2AX phosphorylation (Ser139), p53 and RAD51 expression. Cells were treated with chloroxine (10 $\mu \mathrm{M})$, carboplatin I (50 $\mu \mathrm{M})$, combi. I (chloroxine $10 \mu \mathrm{M}+$ carboplatin $50 \mu \mathrm{M}$ ), carbo II (100 $\mu \mathrm{M}$ ) or combi. II (chloroxine $10 \mu \mathrm{M}+$ carboplatin $100 \mu \mathrm{M})$. Untreated cells were used as control. Quantification was expressed as percentage of cells that showed more than five $\mathrm{YH} 2 \mathrm{AX}$ or RAD51 foci/nuclei at each time point. Data show mean \pm s.d., of individual ROI of duplicate coverslips. At least 100 cells were quantified for each independent experiment (IF and western blot: $n \geq 3$ biological repeats). IF: two-way ANOVA with Tukey post hoc test; ${ }^{* * * *} P<0.0001$, ${ }^{* * *} P<0.001$, ${ }^{* *} P<0.01$ and $P>0.05$ (ns). WB: unpaired $t$ test, ${ }^{* * *} P<$ $0.001{ }^{* *} P<0.01,{ }^{*} P<0.05$ (compared to untreated) and ${ }^{\# \#} P<0.01,{ }^{\#} P<0.05$ compared to carboplatin treated at each time point. 
change following combination treatment (ns) (Fig. 6D). In contrast, Ov4Carbo cells depicted low levels of $\gamma \mathrm{H} 2 \mathrm{AX}$ expression after exposure to carboplatin alone, but again co-treatment with chloroxine significantly potentiated the expression of $\gamma \mathrm{H} 2 \mathrm{AX}$ at both carboplatin doses (chloroxine $10 \mu \mathrm{M}+$ carboplatin $50 \mu \mathrm{M}: P=0.0111$ and chloroxine $10 \mu \mathrm{M}+$ carboplatin $100 \mu \mathrm{M}, P=0.0012$ compared to carboplatin treatment alone). Despite the changes we had observed in RAD51 localisation by IF, total expression of RAD51 by western blot was stable over time and comparable in the two cell lines (Fig. 6D). There was also no significant difference in basal p53 expression between the two cell lines $(P=0.08)$. We did, however, observe increased p53 protein following combination treatment of resistant Ov4Carbo cells (chloroxine $10 \mu \mathrm{M}+$ carboplatin $100 \mu \mathrm{M}, P=0.0318$ ) but not sensitive OVCAR4 cells (Fig. 6D). Together, our results show that chloroxine co-treatment selectively facilitated carboplatin-induced DNA damage in platinum-resistant cancer cells.

\section{Chloroxine + carboplatin abrogates G2/M cell cycle arrest and triggers caspase 3/7-mediated cell death}

To elucidate the downstream effects of DNA damage and p53 stabilisation, we analysed cell cycle and cell death following carboplatin and chloroxine co-treatment. Carboplatin treatment caused OVCAR4 cells to arrest in the $\mathrm{S}$ phase at both 24 (Supplementary Fig. S6) and $48 \mathrm{~h}$ (Fig. 7A, B), with concomitant accumulation of cells in subG1. In contrast, Ov4Carbo cells progressed through the cell cycle into $\mathrm{G} 2 / \mathrm{M}$ ( $>50 \%$ of the population at $48 \mathrm{~h}$ ), despite platinum treatment (Fig. 7A, B). Interestingly, in Ov4Carbo cells, this carboplatin-induced G2/M arrest was abrogated after cotreatment with chloroxine such that cell cycle profile matched that obtained when OVCAR4 cells were treated with carboplatin alone. Together, this suggests that chloroxine could restore the capacity of resistant cells to regulate cell cycle and induce apoptosis following carboplatin treatment. To further investigate this, we quantified caspase 3/7 activity. When OVCAR4 cells were treated with either carboplatin or

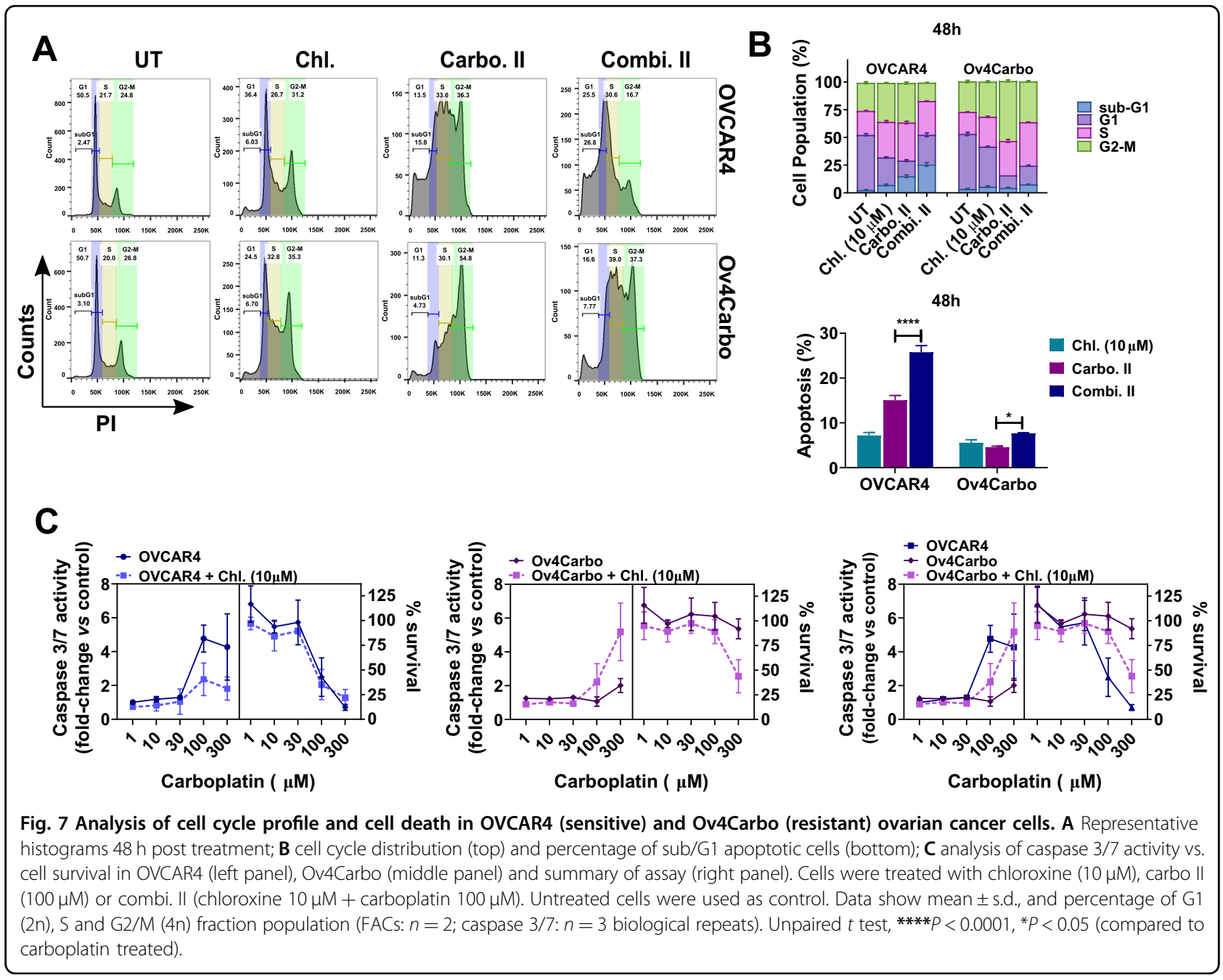


the combination of chloroxine and carboplatin, an increase in caspase $3 / 7$ activity was observed together with an expected decrease in cell survival (Fig. $7 \mathrm{C}$, left panel). There was no difference in caspase $3 / 7$ activity or cell survival in this cell line when carboplatin and the chloroxine/carboplatin combination were compared. In contrast, when Ov4Carbo cells were co-treated with carboplatin and chloroxine, caspase $3 / 7$ activity showed a striking twofold to fivefold increase compared to carboplatin alone (Fig. 7C, middle panel), correlating with the decrease in cell survival and re-sensitisation to carboplatin that we had repeatedly observed. Together, the addition of chloroxine allowed cell cycle re-entry and potentiated carboplatin-induced cell death in platinum-resistant HGSC cells.

\section{Discussion}

Despite HGSC's initial high response rate to platinum chemotherapy, patients eventually succumb to the disease after developing gradual resistance to therapy. New drugs that can circumvent resistance could have important clinical implications. We show here for the first time that the drug chloroxine has a strong synergistic effect with both carboplatin and cisplatin in a range of HGSC cell lines and in vivo models.

Chloroxine is a 8-HQ derivative. This family of drugs have the potential to form metal complexes via copper and zinc binding ${ }^{18,20,21}$, acting as proteasome inhibitors ${ }^{22}$ or triggering apoptosis ${ }^{23,29}$. Although we confirmed the ionophore activity of chloroxine, neither copper complexation nor intracellular uptake of either copper or platinum appeared to mediate the re-sensitisation to platinum that we observed. Equally, we were unable to demonstrate that a predicted pharmacological function for chloroxine as an inhibitor of kappa opioid receptors accounted for drug synergy.

HGSC is characterised by genomic instability with pervasive TP53 mutation ${ }^{30-32}$. Homologous recombination and repair dysfunction is also critical in the pathogenesis of this disease ${ }^{33}$, and cellular responses to carboplatin-induced damage are highly dependent on the proficiency of cell cycle and DDR pathways ${ }^{5,7}$. The status of TP53 has generated controversy around drug response in vitro ${ }^{34}$; thus, it is imperative to use clinically relevant HGSC models such as OVCAR $4^{35}$, in order to understand the relationship of TP53 to mechanisms, including the DDR. Over $60 \%$ of TP53-associated mutations are missense mutations ${ }^{36,37}$, which have been described for OVCAR4 cells ${ }^{37,38}$ and are commonly associated with gain-of-function properties. We show here that chloroxine may well interfere with the DDR, and that stabilisation of p53 in otherwise mutant cells is linked to cell death.

Our data are comparable to other reports ${ }^{7,39-41}$, showing that sensitive OVCAR4 cells can stall DNA replication in $\mathrm{G1} / \mathrm{S}$ phase in response to single-agent platinum treatment. In addition, OVCAR4 cells exhibited minimal RAD51 focus formation, which could potentially indicate a reduced DNA repair capacity and thus higher sensitivity of OVCAR4 cells to platinum drugs. Although there was no difference in total RAD51 protein expression between the two cell lines, Ov4Carbo cells were able to induce RAD51 foci in response to platinum treatment. These enhanced DNA repair dynamics may explain the relative platinum resistance of Ov4Carbo cells and matches with our previous RNASeq analysis that revealed an increase in the DNA recombination pathway in Ov4Carbo compared to OVCAR4 cells ${ }^{13}$.

Chloroxine treatment alone had minimal impact on $\gamma \mathrm{H} 2 \mathrm{AX}$ and RAD51 foci in either cell line. Platinumsensitive OVCAR4 cells were able to efficiently respond to single-agent carboplatin treatment by increasing $\gamma \mathrm{H} 2 \mathrm{AX}$ foci formation at all carboplatin doses and time points tested. In these platinum-sensitive cells, the addition of chloroxine did not increase $\gamma \mathrm{H} 2 \mathrm{AX}$ above the high $\gamma \mathrm{H} 2 \mathrm{AX}$ activation that had already been achieved with carboplatin alone. In contrast, platinum-resistant Ov4Carbo cells did not induce $\gamma \mathrm{H} 2 \mathrm{AX}$ foci in response to the lower dose of $50 \mu \mathrm{M}$ carboplatin, but the addition of chloroxine was able to override this apparent resistance to carboplatin-induced DNA damage and significantly enhance $\gamma \mathrm{H} 2 \mathrm{AX}$ accumulation compared to single-agent carboplatin treatment. Importantly, the very high carboplatin dose of $100 \mu \mathrm{M}$ was able to induce $\gamma \mathrm{H} 2 \mathrm{AX}$ foci even in resistant Ov4Carbo cells and once this had been achieved, chloroxine again did not augment $\gamma \mathrm{H} 2 \mathrm{AX}$ any further. It is interesting to note that by western blot, we did detect significantly elevated $\gamma \mathrm{H} 2 \mathrm{AX}$ protein in Ov4Carbo cells following co-treatment with chloroxine at both carboplatin doses, perhaps reflecting different sensitivity of these two assays. Induction of $\gamma \mathrm{H} 2 \mathrm{AX}$ foci by combination treatment of Ov4Carbo cells was followed by a decrease in RAD51 recruitment. This accumulation of DNA damage would be expected to result in the p53 stabilisation, cell cycle stalling in G1/S and apoptotic cell death that we observed ${ }^{42,43}$. Treatments that can reactivate mutant $\mathrm{p} 53$ protein have been shown to potentiate chemotherapy and induce apoptosis ${ }^{44}$, suggesting that chloroxine may exhibit a similar activity ${ }^{45}$.

In conclusion, we have demonstrated that the nononcological drug chloroxine potentiates the cytotoxicity of carboplatin in resistant subtypes of HGSC. Chloroxine synergy was extended to different platinum agents and a range of cell lines and showed a strong tumour-static effect in vivo. Our data suggest that this synergy is mediated via the persistence and dysfunctional repair of platinum-induced damage, along with p53 stabilisation. We, therefore, propose that chloroxine warrants further investigation as an exciting new combination therapy to target resistant subtypes of HGSC. 


\section{Acknowledgements}

We would like to acknowledge Prof. Fran Balkwill for kindly providing us with the human HGSC cell lines OVCAR4 and COV318 and Dr Ashley Browne for creating the derived resistant cells, Ov4Cis and CovCis. To Dr Danilo Cucchi and Miss Wai Yiu Tse (Betty) for help setting up the immunofluorescence assays. We would also like to thank the biological services unit at charterhouse square and their technicians for all their support with the animal work and Dr Roberto Buccafusca, Mass spectrometry lab manager at the School of Biological and Chemical Sciences, QMUL for his assistance developing our AAS assays.

\section{Author contributions}

V.L.S.: conceptualisation, methodology, data curation, formal analysis, writing original draft, writing-review and editing. J.S.: conceptualisation, methodology, data curation, formal analysis and writing-review. J.H., F.N. and S.M.: data curation, methodology. S.M.: conceptualisation, methodology, formal analysis, project supervision, writing-review and editing. M.L.: conceptualisation, methodology, data curation, formal analysis, writing original draft, writing-review, editing, supervision, funding acquisition and project administration.

\section{Ethics statement}

This paper does not describe studies involving human participants, human data or human tissue. Institutional review board approval was obtained for animal experiments.

\section{Funding}

M.L. and J.S. were supported by a Barts and The London Charity Strategic Research Grant (467/2244). ML and VS received support from a Barts Cancer Institute Incentivisation Award. M.L., F.N., J.I.H. and S.M. were supported by ML's Cancer Research UK Advanced Clinician Scientist Fellowship (C41405/A19694). M.L. received additional support from her Cancer Research UK Clinician Scientist Fellowship (C41405/A13034).

\section{Conflict of interest}

The authors declare no competing interests.

\section{Publisher's note}

Springer Nature remains neutral with regard to jurisdictional claims in published maps and institutional affiliations.

Supplementary information The online version contains supplementary material available at https://doi.org/10.1038/s41419-021-03665-0.

Received: 14 December 2020 Revised: 19 March 2021 Accepted: 22 March 2021

Published online: 14 April 2021

\section{References}

1. Zhang, Y. et al. Global patterns and trends in ovarian cancer incidence: age, period and birth cohort analysis. BMC Cancer 19, 984 (2019).

2. McCluggage, W. G. Morphological subtypes of ovarian carcinoma: a review with emphasis on new developments and pathogenesis. Pathology 43, 420-32 (2011).

3. Gadducci, A. et al. Current strategies for the targeted treatment of high-grade serous epithelial ovarian cancer and relevance of BRCA mutational status. J. Ovarian Res. 12, 9 (2019).

4. Bowtell, D. D. et al. Rethinking ovarian cancer II: reducing mortality from highgrade serous ovarian cancer. Nat. Rev. Cancer 15, 668-79 (2015).

5. Binju, M. et al. Mechanisms underlying acquired platinum resistance in high grade serous ovarian cancer - a mini review. Biochimica et. Biophysica Acta 1863, 371-8 (2019).

6. Ren, J. H. et al. Acquired cisplatin resistance in human lung adenocarcinoma cells is associated with enhanced autophagy. Cancer Biother Radiopharm. 25, 75-80 (2010)

7. Galluzzi, L. et al. Molecular mechanisms of cisplatin resistance. Oncogene $\mathbf{3 1}$ 1869-83 (2012).

8. Loh, S. Y., Mistry, P., Kelland, L. R., Abel, G. \& Harrap, K. R. Reduced drug accumulation as a major mechanism of acquired resistance to cisplatin in a human ovarian carcinoma cell line: circumvention studies using novel platinum (II) and (IV) ammine/amine complexes. Br. J. Cancer 66, 1109-15 (1992).

9. Fink, D., Aebi, S. \& Howell, S. B. The role of DNA mismatch repair in drug resistance. Clin. Cancer Res. 4, 1-6 (1998).

10. Roos, W. P. et al. The translesion polymerase Rev3L in the tolerance of alkylating anticancer drugs. Mol. Pharmacol. 76, 927 (2009).

11. Gadducci, A., Cosio, S., Muraca, S. \& Genazzani, A. R. Molecular mechanisms of apoptosis and chemosensitivity to platinum and paclitaxel in ovarian cancer: biological data and clinical implications. Eur. J. Gynaecol. Oncol. 23, 390-6 (2002).

12. Corsello, S. M. et al. Discovering the anticancer potential of non-oncology drugs by systematic viability profiling. Nat. Cancer 1, 235--248 (2020).

13. Hoare J. I. et al. Platinum resistance induces diverse evolutionary trajectories in high grade serous ovarian cancer. Preprint at https://www.biorxiv.org/content/ 10.1101/2020.07.23.200378v1 (2020).

14. Shahabadi, N. \& Zendehcheshm, S. Evaluation of ct-DNA and HSA binding propensity of antibacterial drug chloroxine: multi-spectroscopic analysis, atomic force microscopy and docking simulation. Spectrochim. Acta A Mol. Biomol. Spectrosc. 230, 118042 (2020).

15. Martin, S. A. et al. Methotrexate induces oxidative DNA damage and is selectively lethal to tumour cells with defects in the DNA mismatch repair gene MSH2. EMBO Mol. Med. 1, 323-37 (2009).

16. Najlah, M. et al. Novel paclitaxel formulations solubilized by parenteral nutrition nanoemulsions for application against glioma cell lines. Int. J. Pharmaceutics 506, 102-9 (2016).

17. Chen, D. et al. Clioquinol, a therapeutic agent for alzheimers disease, has proteasome-inhibitory, androgen receptor-suppressing, apoptosis-inducing and antitumor activities in human prostate cancer cells and xenografts. Cancer Res. 67, 1636 (2007)

18. Daniel, K. G. et al. Clioquinol and pyrrolidine dithiocarbamate complex with copper to form proteasome inhibitors and apoptosis inducers in human breast cancer cells. Breast Cancer Res. 7, R897 (2005).

19. Chou, D. \& Martin, N. J.. CfDCPS, synergism UsGACPfQo, antagonism in drug combinations, IC50 tDo, ED50. ComboSyn Inc Paramus NJ. (2005).Accessed Dec 2020. https://www.combosyn.com/.

20. Ding, W. Q., Liu, B., Vaught, J. L., Yamauchi, H. \& Lind, S. E. Anticancer activity of the antibiotic clioquinol. Cancer Res. 65, 3389-95 (2005).

21. Tardito, S. et al. Copper-dependent cytotoxicity of 8-hydroxyquinoline derivatives correlates with their hydrophobicity and does not require caspase activation. J. Med Chem. 55, 10448-59 (2012).

22. Zhai, S. et al. Tumor cellular proteasome inhibition and growth suppression by 8-hydroxyquinoline and clioquinol requires their capabilities to bind copper and transport copper into cells. JBIC J. Biol. Inorg. Chem. 15, 259-69 (2010).

23. $Y u$, H., Lou, J. R. \& Ding, W.-Q. Clioquinol independently targets NF-KB and lysosome pathways in human cancer cells. Anticancer Res. 30, 2087-2092 (2010).

24. Xiao, M. et al. Comparison of different sample preparation methods for platinum determination in cultured cells by graphite furnace atomic absorption spectrometry. PeerJ 5, e2873 (2017).

25. PubChem [Internet]. Bethesda (MD): National Library of Medicine (US), National Center for Biotechnology Information; 2004-. PubChem Compound Summary for CID 2722, Chloroxine. Available from: https:/pubchem.ncbi.nlm. nih.gov/compound/Chloroxine.

26. Corsello, S. M. et al. Discovering the anticancer potential of non-oncology drugs by systematic viability profiling. Nat. Cancer 1, 235-48 (2020).

27. Munro, T. A. et al. Selective kappa opioid antagonists nor-BNI, GNTI and JDTic have low affinities for non-opioid receptors and transporters. PLOS ONE 8 e70701 (2013).

28. Redon, C. E. et al. Histone $\mathrm{yH} 2 \mathrm{AX}$ and poly (ADP-ribose) as clinical pharmacodynamic biomarkers. Clin. Cancer Res. 16, 4532-4542 (2010).

29. Tuller, E. R. et al. PPARa signaling mediates the synergistic cytotoxicity of clioquinol and docosahexaenoic acid in human cancer cells. Biochem. Pharmacol. 77, 1480-6 (2009).

30. Yang-Hartwich, Y. et al. p53 protein aggregation promotes platinum resistance in ovarian cancer. Oncogene 34, 3605-16 (2015).

31. Cooke, S. L. \& Brenton, J. D. Evolution of platinum resistance in high-grade serous ovarian cancer. Lancet Oncol. 12, 1169-74 (2011).

32. Network CGAR. Integrated genomic analyses of ovarian carcinoma. Nature 474, 609 (2011).

33. Damia, G. \& Broggini, M. Platinum resistance in ovarian cancer: role of DNA repair. Cancers 11, 119 (2019).

34. Leroy, B. et al. Analysis of TP53 mutation status in human cancer cell lines: a reassessment. Hum. Mutat 35, 756-65 (2014). 
35. Domcke, S., Sinha, R., Levine, D. A., Sander, C. \& Schultz, N. Evaluating cell lines as tumour models by comparison of genomic profiles. Nat. Commun. 4, 2126 (2013).

36. Bell, D. et al. Integrated genomic analyses of ovarian carcinoma. Nature 474, 609-15 (2011).

37. Ghannam-Shahbari, D. et al. PAX8 activates a p53-p21-dependent proproliferative effect in high grade serous ovarian carcinoma. Oncogene 37, 2213-24 (2018).

38. Tym, J. E. et al. canSAR: an updated cancer research and drug discovery knowledgebase. Nucleic Acids Res. 44, D938-D43 (2015).

39. Basu, A. \& Krishnamurthy, S. Cellular responses to cisplatin-induced DNA damage. J. Nucleic Acids 2010, 201367 (2010).

40. Gonzalez-Rajal, A., Hastings, J. F., Watkins, D. N., Croucher, D. R. \& Burgess, A. Breathing New life into the mechanisms of platinum resistance in lung adenocarcinoma. Front. Cell Dev. Biol. 8, 305 (2020).
41. Bruno, P. M. et al. A subset of platinum-containing chemotherapeutic agents kills cells by inducing ribosome biogenesis stress. Nat. Med. 23, 461-71 (2017)

42. Xie, X., He, G. \& Siddik, Z. H. Cisplatin in combination with MDM2 inhibition downregulates Rad51 recombinase in a bimodal manner to inhibit homologous recombination and augment tumor cell kill. Mol. Pharmacol. 97, 237-249 (2020).

43. Hine, C. M., Seluanov, A. \& Gorbunova, V. Use of the Rad51 promoter for targeted anti-cancer therapy. Proc. Natl Acad. Sci. USA 105, 20810-5 (2008).

44. Fransson, Å. et al. Strong synergy with APR-246 and DNA-damaging drugs in primary cancer cells from patients with TP53 mutant high-grade serous ovarian cancer. J. Ovarian Res. 9, 27 (2016).

45. Katsuyama, M. et al. Clioquinol induces DNA double-strand breaks, activation of ATM, and subsequent activation of p53 signaling. Toxicology 299, 55-9 (2012). 